\title{
Enzyme catalysis prior to aromatic residues: reverse engineering of a dephosphoCoA kinase
}

Mikhail Makarov*1,2, Jingwei Meng*3, Vyacheslav Tretyachenko ${ }^{1,2}$, Pavel Srb ${ }^{4}$, Anna Březinová ${ }^{5}$, Valerio Guido Giacobelli ${ }^{1}$, Lucie Bednárová ${ }^{4}$, Jiří Vondrášek ${ }^{4}$, A. Keith Dunker ${ }^{3}$ \& Klára Hlouchová ${ }^{1,4}$

${ }^{1}$ Department of Cell Biology, Faculty of Science, Charles University, Biocev, Prague 2, Czech Republic.

${ }^{2}$ Department of Biochemistry, Faculty of Science, Charles University, Hlavova 8, 128 00, Prague 2, Czech Republic.

${ }^{3}$ Center for Computational Biology and Bioinformatics, Indiana University School of Medicine, Indianapolis, Indiana, USA

${ }^{4}$ Institute of Organic Chemistry and Biochemistry IOCB Research Centre \& Gilead Sciences, Academy of Sciences

of the Czech Republic, Flemingovo nám. 2, 166 10, Prague, Czech Republic

${ }^{5}$ Proteomics Core Facility, BIOCEV, Faculty of Science Charles University, Prague, Czech Republic.

* shared authorship

Correspondence: klara.hlouchova@natur.cuni.cz, kedunker@iu.edu

Keywords: genetic code evolution, protein disorder, catalysis evolution, aromatic amino acids

\section{Significance}

All extant proteins rely on the standard coded amino acid alphabet. However, early proteins lacked some of these amino acids that were incorporated into the genetic code only after the evolution of their respective metabolic pathways, aromatic amino acids being among the last additions. This is intriguing because of their crucial role in hydrophobic core packing, indispensable for enzyme catalysis.

We designed two aromatics-less variants of a highly conserved enzyme from the CoA synthesis pathway, capable of enzyme catalysis and showing significant ordering upon substrate binding. To our knowledge, this is the first example of enzyme catalysis in complete absence of aromatic amino acids and presents a possible mechanism of how aromatics-less enzymes could potentially support an early biosphere.

\section{Abstract}

It is well-known that the large diversity of protein functions and structures is derived from the broad spectrum of physicochemical properties of the 20 canonical amino acids. According to the generally accepted hypothesis, protein evolution was continuously associated with enrichment of this alphabet, increasing stability, specificity and spectrum of catalytic functions. Aromatic amino acids are considered the latest addition to genetic code.

The main objective of this study was to test whether enzymatic catalysis can spare the aromatic amino acids (aromatics) by determining the effect of amino acid alphabet reduction on 
structure and function of dephospho-CoA kinase (DPCK). We designed two mutant variants of a putative DPCK from Aquifex aeolicus by substituting (i) Tyr, Phe and Trp or (ii) all aromatics (including His), i.e. $\sim 10 \%$ of the total sequence. Their structural characterization indicates that removal of aromatic amino acids may support rich secondary structure content although inevitably impairs a firm globular arrangement. Both variants still possess ATPase activity, although with 150-300 times lower efficiency in comparison with the wild-type phosphotransferase activity. The transfer of the phosphate group to the dephospho-CoA substrate is however heavily uncoupled and only one of the variants is still able to perform the reaction.

Here we provide support to the hypothesis that proteins in the early stages of life could support at least some enzymatic activities, despite lower efficiencies resulting from the lack of a firm hydrophobic core. Based on the presented data we hypothesize that further protein scaffolding role may be provided by ligands upon binding.

\section{Introduction}

The extant alphabet of canonical amino acids was apparently selected in the first $10-15 \%$ of Earth history from a plethora of amino acids (i) available on primordial Earth and (ii) synthesized through gradually developing metabolic pathways (1). Recent analyses reveal that, compared to alternatives, it composes an unusually good repertoire of physical properties (2-4). Even entirely random sequences built from the canonical alphabet give rise to secondary structure-rich proteins (5). Nevertheless, soluble and well-expressing proteins have been successfully recovered from random libraries of simpler alphabet of evolutionary early amino acids $(6,7)$. However, the stage of the amino acid alphabet evolution at which proteins could have gained dominance in binding and catalysis remains unclear.

Aromatic amino acids are considered among the last additions to the genetic coding system, i.e. to the canonical amino acid alphabet $(8,9)$. Because of their relatively high redox reactivity, their fixation in the genetic code could be driven by the biospheric oxygen (10). There is recent evidence that for some of the aromatics (Tyr and Trp) this possibly happened even in the post-LUCA period $(10,11,12)$. These proposals suggest that there was a time when living cells existed without aromatic amino acids.

Even though different reduced sets (of 7-13) of the amino acid alphabet have been shown or predicted to be sufficient for protein folding and catalysis, to our knowledge, none of the experimental studies recovered enzyme activity in complete absence of aromatics (13-18). Computational inquiry indicates that the aromatics are the strongest structure promoters among the 20 amino acid alphabet (19). This conclusion is consistent with observation that aromatics are mostly clustered within the hydrophobic cores of structured proteins and with quantum chemistry calculations showing the interactions between aromatics stronger and more specific than aliphatic side chains interactions (20). A comparison of the structure/disorder propensities of the 20 amino acids with the chronology of amino acid inclusion into the genetic code indicates that the earliest amino acids are strongly disorder-promoting while the last to be added, e.g. the aromatics, are among the most strongly structure-promoting $(9,19,21)$. Indeed, aromatics are heavily underrepresented in intrinsically disordered proteins and regions (IDPs and IDRs), i.e. proteins that 
lack stable 3D structure and yet frequently carry out crucial biological functions, associated with signaling and regulation in particular $(22,23)$. While some functions can thus be delivered even in lack of tertiary structure, it remains unclear if and how early enzymes could achieve specific catalysis without a stable hydrophobic core and aid of aromatic residues.

Here, we perform an analysis of structure/function consequences of amino acid reduction by aromatic amino acids. As an exemplary target, we choose a highly conserved metabolic enzyme from a hyperthermophilic bacteria (and hence of potential relevance to early life) - an enzyme that catalyzes the final step of coenzyme A biosynthesis, which is known to be essential for all life and considered among the most ancient cofactors. We present evidence that enzyme catalysis can occur in the absence of aromatic amino acids and a firm hydrophobic core, formation of which can be induced upon ligand binding.

\section{Results}

\section{Target selection by analysis of LUCA proteins}

In order to identify conserved structured protein families, we applied our VSL2B disorder predictor (24) to a collection of last universal common ancestor (LUCA) assigned proteins identified by their ubiquity across all kingdoms of cellular life (25). The non-enzymes, mostly ribosomal or other RNA binding proteins, were all predicted to be massively disordered while the enzymes were predicted to be structured. These modern-day versions of the ancient enzymes all contain multiple aromatic residues, we have been unable to identify a single efficient modern enzyme that lacks multiple aromatic residues. Among the LUCA assigned enzymes identified by Brooks and Fresco, we selected dephospho-CoA kinase (DPCK) for further study because it has the lowest number of aromatic amino acids (25). Other advantages of this choice are that there are multiple 3D structures of different DPCK family members and that the DPCK proteins have relatively small sizes.

\section{Sequence design, expression and purification of DPCK variants}

To evaluate the significance of aromatic amino acids for the structure and function of DPCK, the PDB database was first searched for solved structures of confirmed and putative DPCKs from different thermophilic bacterial species (Supplementary Table S1). An initial test of expression, solubility, ease of large-scale purification and DPCK activity lead to selection of a putative DPCK from Aquifex aeolicus (PDB ID: 2IF2) for this experiment (Supplementary Table S1).

Mutant variants of DPCK were designed as follows. First, all Phe, Tyr and Trp residues were substituted by (i) Leu residues (DPCK-LH) and (ii) non-aromatic amino acids based on best preservation of thermodynamic stability (DPCK-MH) using the Hot Spot Wizard server (26). Second, all of the above amino acids plus His were substituted using the same logic, producing DPCK-L and DPCK-M variants respectively. DPCK-LH/MH and DPCK-L/M variants thus have $10 \%$ and $11 \%$ of the total protein sequence substituted, respectively. Synthetic genes of all these variants were subcloned and expressed in $E$. coli with a C-terminal histidine tag using standard protocols (see Methods for details). Upon preliminary purification and DPCK activity 
characterization, only DPCK-LH and DPCK-M variants were selected for detailed characterization (Fig. 1). Intriguingly, DPCK-L mutant had a very poor expression (even after optimization attempts) in E. coli and both DPCK-L and DPCK-MH mutants did not have any measurable DPCK-related activity (Supplementary Table S2).

DPCK-WT, -LH and -M variants were purified to homogeneity using a three-step purification protocol (Supplementary Fig. S1). Prior to further experiments, the identity, molecular weight and oligomeric status of the protein variants were tested by mass spectrometry and analytical size exclusion chromatography (Supplementary Fig. S1). All protein variants were of expected molecular weight. DPCK-WT and -LH eluted as monomers while the -M variant resembles either a dimeric or disordered monomeric form in the elution profile.

\section{Enzyme activity characterization}

The specificity and rates of enzymatic reactions of the DPCK variants were initially characterized using a commercial kit relying on a coupling detection of ADP, one of the reaction products. In the assay, the ADP is converted to pyruvate which is then quantified by a fluorometric method. Because the assay was performed at two regimes (varying the concentration of ATP or dCoA), it was possible to observe significant differences in the reaction specificity of the variants (Fig 2).

DPCK-WT has similar catalytic efficiency for both ATP and dCoA as substrates while the ATP hydrolysis activity is dependent on $\mathrm{dCoA}$ binding (Fig. 2). The herein measured catalytic efficiency of the reaction ( 2 and $3.5 \times 10^{-6} \mathrm{M}^{-1} \mathrm{~min}^{-1}$ for $\mathrm{dCoA}$ and ATP, respectively) is similar to previously reported efficiency of DPCK from E. histolytica (27). In contrast, the catalytic efficiency of DPCK-LH and DPCK-M are significantly lower $\left(2.2 \times 10^{-8}\right.$ and $0.7 \times 10^{-8} \mathrm{M}^{-1} \mathrm{~min}^{-1}$ for ATP, respectively), resulting in a decreased turnover number (Fig. 2 and Supplementary Fig. S2). In the case of DPCK-M, these rates are independent of varying concentrations of $\mathrm{dCoA}$ implying an impaired efficiency of the phosphate transfer, i.e. only phosphatase activity is observed (Fig. 2B). While both DPCK-LH and -M variants have the capacity to hydrolyze ATP in the absence of dCoA (unlike DPCK-WT), DPCK-LH has also the dCoA dependent activity (above app. 80 $\mu \mathrm{M}$ dCoA) with $\mathrm{K}_{M}$ bigger than $200 \mu \mathrm{M}$. This activity has been difficult to measure using the commercial kit due to the concentration range limitation. In order to confirm the identity of the reaction products and reaction specificity, the DPCK reactions were performed at a fixed substrate concentration above the DPCK-WT $\mathrm{K}_{M}$ value (where the reaction rate is less dependent or independent of substrate concentration) in order to reach sufficient substrate conversion for detection of the products using HPLC-MS analysis. This analysis detected significant CoA formation only in the reaction catalyzed by DPCK-WT and 100x lower formation was detected in the reactions catalyzed by DPCK-LH (Supplementary Fig. S2).

\section{Secondary and tertiary structure characterization}

Using the purified proteins, their structural properties were investigated using electronic circular dichroism (ECD), NMR and limited proteolysis. 
ECD spectrum of DPCK-WT (Fig. 3A) with comparable intensity of negative maxima at 209 and $225 \mathrm{~nm}$ and with intense positive maximum at $195 \mathrm{~nm}$ indicates relatively high partition of $\alpha$-helical structure $(\sim 45 \%)$. This is confirmed by the numerical data analysis and agrees with the secondary structure assignment of the X-ray structure (PDB code 2IF2) (Supplementary Table S3). In the case of DPCK-LH, the first negative maximum is blue-shifted to $207 \mathrm{~nm}$ and its intensity is comparable to that of the second negative maximum at $225 \mathrm{~nm}$. This together with the positive maximum at $195 \mathrm{~nm}$ (almost half intensity compared to CD spectrum of DPCK-WT) reveals a significant content of $\alpha$-helical structure $(\sim 40 \%)$ together with more pronounced partition of $\beta$-sheet structure, confirmed also by the numerical data analysis (Supplementary Table S3). ECD spectrum of DPCK-M has the first negative maximum also blue-shifted up to $205 \mathrm{~nm}$ but this spectral band is more intense compared to the second negative maximum at 222 $\mathrm{nm}$, which could imply possible formation of 310 -helical structure as well as enrichment of unordered structure. The overall spectral shape and mainly spectral intensity of a positive spectral band at $192 \mathrm{~nm}$ could be due to a relatively high portion of $\beta$-sheet structure (Supplementary Table S3).

To estimate the influence of amino acid mutation on overall protein structure stability, the protein was unfolded with urea in concentration ranging from $0 \mathrm{mM}$ to $10 \mathrm{mM}$ and was further studied using CD spectroscopy. While DPCK-WT ECD spectrum remains constant upon mild urea titration (up to $10 \mathrm{mM}$ ), the urea titration spectra indicate a molten globular feature of in both DPCK-LH and -M variants (Fig. 3B). The DPCK-M variant, in which all aromatics were replaced, exhibited a much stronger effect than $-\mathrm{LH}$ variant.

Similarity of structural resemblance of DPCK-LH and DPCK-WT was further confirmed by $1 \mathrm{D}$ and 2D HN NMR spectra. DPCK-WT spectrum has a good signal dispersion in the -NHregion (6-9 ppm) and clear signals near 1 ppm indicative of methyl groups in the hydrophobic core, all features corresponding to a well-folded protein. While the signal of the methyl groups in the hydrophobic core is absent in the DPCK-LH variant spectrum (as expected from the removal of aromatic residues), the signal dispersion in the - $\mathrm{NH}$ - region implies that the - $\mathrm{LH}$ variant is at least partially folded, in contrast with that of the $-\mathrm{M}$ variant where the signal in the same region is less dispersed, implying lack of tertiary structure (Fig. 3C and Supplementary Fig. S3). Based on the analyses of N-edited 3D NOESY spectra, the following counts of $\alpha$-helical peaks at 131, 57 and 14 for DPCK- WT, -LH and -M variants, respectively (Supplementary Table S3).

The tertiary structure of the proteins was additionally characterized by limited proteolysis by endoproteinase Lys-C as its cleavage site map is conserved among all studied variants (Supplementary Fig. S4). DPCK-WT shows high resistance to proteolytic digestion during the whole-time scale of the limited proteolysis experiment, reflecting its globular structure. In contrast, both mutant variants are gradually digested by Lys-C over time and the amounts of the intact DPCK-LH and DPCK-M decrease exponentially over time. While relatively large cleaved fragments with the approximate size of $15 \mathrm{kDa}$ can be observed during proteolysis of DPCK-LH, no large cleavage fragments are detected during proteolysis of DPCK-M, an indication of its loose or absent tertiary structure (Fig. 4).

In summary, DPCK-LH variant (which has all the aromatic amino acids substituted by leucine) shows relatively high conservation of secondary structure but a loose tertiary structure (probably of molten globular nature) when compared with the -WT protein. On the other hand, 
both secondary and tertiary structures of DPCK-M variant are severely impaired, in which all histidines were substituted in addition to aromatics.

\section{Structural characterization of ATP binding}

For an efficient phosphorylation reaction, the ATP gamma-phosphate has to be protected from a nucleophilic attack by water molecules. DPCK active site must therefore be shielded from water once ATP molecule is bound. Similar to other kinases, this conformational change of DPCK, induced by ATP binding, has been described previously (28).

To study the structural changes of DPCK variants upon ATP binding, 2D HN NMR spectra were collected in response to ATP titration (see Supplementary Fig S5). While the NMR spectra of the DPCK-M variant are of generally low quality, which is probably caused by complex dynamics on the millisecond time-scale making the protein signals invisible for NMR spectroscopy, the spectra of both DPCK-WT and -LH variants show expected perturbations upon ATP titration. For DPCK-WT we observe typical examples of slow exchange behavior, where only free and bound forms are observed with peak intensity proportional to the population. Interestingly, for the DPCK-LH variant, we typically observed examples of fast exchange with only a single peak visible at a given protein:ATP ratio, although examples of slow exchange are observed as well (Fig. 5A). This suggests that compared to the WT:ATP interaction, an additional process occurs during DPCK-LH titration with ATP.

To further investigate this intriguing observation, DPCK-WT and -LH (i.e. those variants that are capable of phosphotransferase activity that requires a hydrophobic core) structural response to substrate binding was tested using dynamic light scattering and ANS titration. The steady-state fluorescence measurements support the molten globule nature of DPCK-LH variant since it shows higher fluorescence intensity values in comparison with DPCK-WT, resulting from the high affinity of ANS to the exposed hydrophobic core of molten globular intermediates (29). While the fluorescence intensity decreases for both variants upon substrate binding, this change is significantly more dramatic for DPCK-LH (Fig. 5C). ATP (out of the two substrates) has a remarkable effect on additional folding of DPCK-LH protein, explaining its ability to perform the phosphotransferase activity despite its molten globular nature in the free state. Both 2D HN NMR and ANS titration observations were further supported by DLS measurements where the mean hydrodynamic radius of DPCK-LH was recorded to be reduced by $\sim 20 \%$ and reached that of DPCK-WT value upon ATP addition (Fig. 5B).

\section{Discussion}

Aromatic residues are essential for formation of a stable hydrophobic core of extant proteins (20). At the same time, tight protein folding is frequently required for enzyme catalysis even though most enzymes undergo dynamic structural changes during the process. With aromatics being apparently the latest addition to the amino acid alphabet, how specific protein 
catalysis could be achieved in their absence remains unclear. The work reported here sheds some light on this problem.

To examine the contribution of the aromatic amino acids to enzyme catalysis, we performed a detailed analysis of two aromatics-less mutants of the Aquifex aeolicus DPCK where (i) all Phe, Tyr and Trp residues were substituted by Leu residues (DPCK-LH), and (ii) all Phe, Tyr, Trp and His were substituted by non-aromatic amino acids based on predicted preservation of thermodynamic stability (DPCK-M). According to the Trifonov's chronology of amino acid incorporation into genetic coding, His was among the last amino acids added (9). On the other hand, according to the order-disorder propensity scale, His is among the most disorder-promoting amino acids, likely due to its significant positive charge and the two hydrogen-bonding nitrogen groups that could promote structural instability by bond switching (19). In contrast to the tendency of His to induce disorder, in the presence of divalent cations, especial zinc, His often plays in role in inducing structure due to its metal ion coordination.

The wild type variant of DPCK performs phosphotransferase activity from ATP to dCoA where dCoA acts as the leading substrate and ATP does not get hydrolysed in its absence (30). The unliganded DPCK is a well folded protein with high $\alpha$-helical content, its domain movements upon ATP binding play a crucial role during catalysis (28). None of the aromatic amino acid residues has been reported essential for the ligand binding and catalysis (30).

Interestingly, the DPCK-M variant (selected for best predicted preservation of thermodynamic stability) had a more impaired structural integrity than DPCK-LH. This may be either the consequence of the specific substitutions or the indispensability of the DPCK's His residues. Given the speculative role of His for hydrogen bond switching, it would be interesting to determine whether His plays a role in facilitating the domain movements needed for catalysis. In contrast, CD and NMR measurements of the DPCK-LH variant showed a similar content of secondary structure to the wild type protein but limited proteolysis, CD urea titration and 2D NMR all imply its molten globule tertiary conformation. DPCK-M variant has no measurable phosphotransferase activity while both of the mutant variants are able to hydrolyse ATP even in the absence of $\mathrm{dCoA}$. This is likely due to the loss of structural orchestration of the catalytic events and demonstrates that some activities can be performed even in the absence of a firm hydrophobic core. However, this is probably untrue for the phosphotransferase activity where the gamma-phosphate has to be protected from a nucleophilic attack by water molecules in order to be efficiently transferred to the desired substrate. DPCK-LH variant is still able to perform this activity although with significantly lower efficiency $(\sim 100 \times)$ compared with the wild type protein. Similar to the wild type protein, slow-exchange behavior is observed in the NMR spectra upon ATP titration, representing the ATP-induced change in structural conformation. However, the DPCK-LH variant undergoes significant additional folding upon ATP binding, explaining its ability to perform the phosphotransferase reaction. This ligand-induced folding scenario is in agreement with previously reported engineered molten globular enzymes (31-33). In a wellstructured, lock and key type enzyme, most of the binding energy translates into substrate distortion so large rate accelerations can be achieved. However, for molten globular enzymes such as the one described here, some of the binding energy is needed to induce protein folding so one expects a reduced rate acceleration as we have found here. 
The study of the engineered molten globular enzyme (32) includes the hypothesis that modern enzymes evolved from molten globular precursors. If the earliest cells indeed existed without aromatics, then the data in this paper adds weight to this evolutionary scenario of molten globular polypeptide $\rightarrow$ molten globular enzyme $\rightarrow$ modern enzyme, where the last step is enabled by the expansion of the genetic code to include the aromatic residues. In this view, the evolutionary advantage of adding the aromatic amino acids was to enable the formation of tightly structured proteins with an accompanying high performance catalysis.

To further test this idea, work in progress is to use bioinformatics tools to carry out disorder prediction with VSL2B on DPCK and the other identified ancient enzymes with their modern sequences and with their aromatics replaced by Leu. All of the ancient enzymes so far tested are predicted to be structured with the aromatics and disordered without these residues. The next step will be to apply additional bioinformatic tools that distinguish molten globules from other types of disorder (34)

In summary, we report an enzyme without aromatic amino acids that is still capable of a specific, hydrophobic pocket dependent catalysis. This enzyme is rich in secondary structure but exhibits a molten globule conformation in an unliganded form. Our study provides evidence that a tightly packed protein environment can form upon its ligand binding. This phenomenon could be relevant in the early stages of enzyme catalysis before the fixation of the contemporary amino acid alphabet.

\section{Methods}

\section{Plasmid preparation}

DPCK genes for DPCK-WT, DPCK-LH, -L, -MH and -M were amplified by PCR using Pfu-X DNA polymerase (Jena Bioscience, Germany) according to the following program: an initial denaturation at $95{ }^{\circ} \mathrm{C}$ for $2 \mathrm{~min}$; followed by the 32 cycles of denaturation at $95{ }^{\circ} \mathrm{C}$ for 30 sec; annealing at $56^{\circ} \mathrm{C}$ for $30 \mathrm{sec}$; and elongation at $68^{\circ} \mathrm{C}$ for $30 \mathrm{sec}$; and a final extension at 68 ${ }^{\circ} \mathrm{C}$ for $2 \mathrm{~min}$. The PCR amplification for all three genes was performed with the same set of primers: forward, 5'-AAAAACATATGAAACGTATCGGTCTGACC-3', and reverse, 5'AAAAACTCGAGTTCCAGCGGGTCACGG-3'. The PCR fragments were digested with XhoI (New England BioLabs, USA) and NdeI (New England BioLabs, USA), purified with Monarch PCR \& DNA Cleanup Kit (New England BioLabs, USA) and cloned into PET-24a (+) Cterminal-histidine-tag vector (Novagen, Germany), which was digested by XhoI and NdeI and dephosphorylated by Antarctic Phosphatase (New England BioLabs, USA) prior to ligation.

The plasmids were introduced into One Shot TOP10 Chemically Competent E. coli cells (Thermo Fisher Scientific, USA) by heat shock protocol at $42{ }^{\circ} \mathrm{C}$ for $60 \mathrm{sec}$, and the cells were grown overnight at $37^{\circ} \mathrm{C}$ on LB agar plates containing $50 \mu \mathrm{g} / \mathrm{ml}$ of kanamycin (Sigma Aldrich, USA). A single colony was selected, cells were grown overnight at $37^{\circ} \mathrm{C}$ in $5 \mathrm{ml}$ of LB Broth (Sigma Aldrich, USA) supplemented with $50 \mu \mathrm{g} / \mathrm{ml}$ of kanamycin (Sigma Aldrich, USA) and plasmid DNA was isolated and analyzed by Sanger sequencing.

\section{Protein expression and purification}


Isolated plasmids were introduced into E. Coli BL21 (DE3) cells (Thermo Fisher Scientific, USA), and the cells were grown overnight at $37{ }^{\circ} \mathrm{C}$ in $5 \mathrm{ml}$ of LB Broth (Sigma Aldrich, USA) in the presence of $50 \mu \mathrm{g} / \mathrm{ml}$ of kanamycin. The overnight cultures were used to inoculate $500 \mathrm{ml}$ of fresh medium, and the culture was propagated at $37{ }^{\circ} \mathrm{C}$ at $220 \mathrm{rpm}$ shaking. When OD $_{60}$ reached 0.7-0.8, isopropyl $\beta$-D-thiogalactopyranoside (IPTG, Sigma Aldrich, USA) was added to final concentration of $0.5 \mathrm{mM}$ and the cultivation was continued for $4 \mathrm{~h}$ at $37^{\circ} \mathrm{C}$. The cells were harvested by centrifugation at $3000 \times \mathrm{g}$ for $20 \mathrm{~min}$ at $4{ }^{\circ} \mathrm{C}$. The cell pellets were resuspended in $15 \mathrm{ml}$ of lysis buffer $(20 \mathrm{mM}$ Tris $(\mathrm{pH} 8.0), 20 \mathrm{mM} \mathrm{NaCl}$, and $1 \mathrm{mM}$ of $\beta$ mercaptoethanol) with one tablet of EASYpack protease inhibitor cocktail (Sigma Aldrich, USA), incubated with $50 \mu \mathrm{g} / \mathrm{ml}$ of lysozyme and $6 \mathrm{U}$ of RNase-free DNase I (Jena Bioscience, Germany) at room temperature for $30 \mathrm{~min}$, sonicated on ice at $1.5 \mathrm{~W}$ (18 cycles, $10 \mathrm{sec}$ on, $20 \mathrm{sec}$ off) and centrifuged at $35000 \times \mathrm{g}$ for $30 \mathrm{~min}$ at $4{ }^{\circ} \mathrm{C}$. After, Tween-20 (Sigma Aldrich, USA) was added to supernatants to the final concentration of $0.1 \%(\mathrm{v} / \mathrm{v})$, and the crude lysates were applied to $5 \mathrm{ml}$ HiTrap Capto Q column (GE Healthcare Life Sciences, USA) equilibrated with 5 volumes of buffer A (20 mM Tris (pH 8.0), $20 \mathrm{mM} \mathrm{NaCl}, 1 \mathrm{mM}$ beta-mercaptoethanol and $0.1 \%$ (v/v) Tween-20). Then, the DPCK proteins were eluted with $0-50 \%$ gradient of buffer B (20 mM Tris ( $\mathrm{pH} \mathrm{8.0),1} \mathrm{M} \mathrm{NaCl,} 1 \mathrm{mM}$ beta-mercaptoethanol and $0.1 \%$ (v/v) Tween-20), and fractions from $15 \%$ to $35 \%$ of buffer B were collected and applied to 5ml HisTrap HP column (GE Healthcare Life Sciences, USA) equilibrated with 5 volumes of buffer C (20 mM Tris (pH 7.6), $500 \mathrm{mM} \mathrm{NaCl}, 10 \mathrm{mM}$ imidazole, $1 \mathrm{mM}$ beta-mercaptoethanol and $0.1 \%$ (v/v) Tween-20). The column was washed with $3 \%$ of buffer D $(20 \mathrm{mM}$ Tris $(\mathrm{pH} 7.6), 500 \mathrm{mM} \mathrm{NaCl}, 500 \mathrm{mM}$ imidazole, $1 \mathrm{mM}$ beta-mercaptoethanol and $0.1 \%(\mathrm{v} / \mathrm{v})$ Tween-20) to remove unbound proteins, and the DPCK proteins were eluted with $0-50 \%$ gradient of buffer D. Fractions from $20 \%$ to $30 \%$ of buffer D were collected, concentrated up to $0.5 \mathrm{ml}$ by centrifugation using $4 \mathrm{ml}$ Amicon Ultra centrifugal units (MWCO 10 000, Millipore, USA) and applied to Superdex 75 10/300 GL column (GE Healthcare Life Sciences, USA) equilibrated with 2 column volumes of buffer E (50 $\mathrm{mM}$ Tris (pH 7.6), $500 \mathrm{mM} \mathrm{NaCl}, 20 \mathrm{mM} \mathrm{KCl}, 10 \mathrm{mM} \mathrm{MgCl}_{2}$ and $0.5 \mathrm{mM}$ DTT). The DPCK variants were eluted as single peaks with approximate sizes of $29 \mathrm{kDa}$ (DPCK-WT), $33 \mathrm{kDa}$ (DPCK-LH) and $55 \mathrm{kDa}$ (DPCK-M). Molecular weights were estimated using Gel filtration low molecular weight calibration kit (GE Healthcare Life Sciences, USA). After the confirmation of proteins integrity and purity by SDS-PAGE analysis on 14\% acrylamide gel, the purified proteins were concentrated up to $10 \mathrm{mg} / \mathrm{ml}$ concentration and aliquoted. The aliquots were flash frozen in liquid nitrogen and stored at $-80^{\circ} \mathrm{C}$.

\section{Basic biophysical characterization}

The identities and molecular weights of purified proteins were confirmed by mass spectrometry using UltrafleXtreme MALDI-TOF/TOF mass spectrometer (Bruker, Germany) according to the standard procedure. Protein concentrations were determined by amino acid analysis using a Biochrom 30+ Series Amino Acid Analyser (Biochrom, UK).

The size distribution of protein samples was characterized using dynamic light scattering (DLS) technique. Protein samples were diluted in PBS buffer $(11.8 \mathrm{mM}$ phosphate buffer $(\mathrm{pH}$ 7.6), $137 \mathrm{mM} \mathrm{NaCl}, 5 \mathrm{mM} \mathrm{MgCl} 2,2.7 \mathrm{mM} \mathrm{KCl}$ and $0.5 \mathrm{mM}$ DTT) to the final concentration of $0.5 \mathrm{mg} / \mathrm{ml}$ and centrifuged at $25000 \times \mathrm{g}$ for $30 \mathrm{~min}$ at $4{ }^{\circ} \mathrm{C}$. In order toremove dust particles, samples were filtered using $0.22 \mu \mathrm{m}$ Ultrafree-MC centrifugation filters (Millipore, USA). The DLS measurements were performed in a quartz glass cuvette (light path $10 \mathrm{~mm}$ ) at $18{ }^{\circ} \mathrm{C}$ using a 
laser spectroscatter-201 system (RiNA GmbH Berlin, Germany). A series of 35 measurements with a sampling time of $30 \mathrm{sec}$ and a wait time of $1 \mathrm{sec}$ was conducted for each sample. A diode laser of wavelength $685 \mathrm{~nm}$ and an optical power of $30 \mathrm{~mW}$ was used as the source. The scattered light was collected at a fixed scattering angle of 90 , and the autocorrelation functions were analyzed with the program CONTIN to obtain hydrodynamic radius distributions. DLS measurements were performed for protein samples in the presence of $200 \mu \mathrm{M}$ ATP to estimate the effect of ATP binding on the hydrodynamic radius of proteins.

\section{Enzyme assays}

DPCK activities of recombinant proteins were measured by a coupling assay using ADP Quest Assay kit (Eurofins DiscoverX, USA) according to the manufacturer's instructions. Enzymatic assays were carried out using $80 \mathrm{ng}(32 \mathrm{nM})$ of DPCK-WT, $500 \mathrm{ng}(214 \mathrm{nM})$ of DPCK-LH and $900 \mathrm{ng}(386 \mathrm{nM})$ of DPCK-M and two kind of substrates, 0-200 $\mu \mathrm{M}$ for dephospho-CoA (dCoA) at $200 \mu \mathrm{M}$ ATP and 0-200 $\mu \mathrm{M}$ for ATP without and with $200 \mu \mathrm{M} \mathrm{dCoA}$ to estimate ATPase and phosphotransferase activities of enzymes. All reactions were performed in assay buffer containing $15 \mathrm{mM}$ Hepes (pH 7.4), $20 \mathrm{mM} \mathrm{NaCl}, 1 \mathrm{mM}$ EGTA, $0.02 \%$ Tween$20,10 \mathrm{mM} \mathrm{MgCl}_{2}$, and $0.1 \%$ bovine gamma globulin in 96-well black microplate with $40 \mu \mathrm{l}$ total volume. After $20 \mu \mathrm{l}$ of reagent A and $40 \mu \mathrm{l}$ of reagent B were added, the plates were heated at 37 ${ }^{\circ} \mathrm{C}$ for $10 \mathrm{~min}$, and the reactions were started by adding ATP. The fluorescent intensity signal was measured at $37{ }^{\circ} \mathrm{C}$ in kinetic mode with 2 min intervals using CLARIO star microplate reader (BMG LABTECH, Germany) at excitation/emission wavelengths of 530/590 nm. The kinetic parameters were calculated using the non-linear regression function using the single saturating concentrations of substrates. Substrate conversion did not exceed $10 \%$. The experiments were repeated three times, and kinetic values are presented as the means $\pm \mathrm{SE}$.

HPLC-MS analysis was used for comparative detection of the reaction analytes. For this purpose, $100 \mu \mathrm{l}$ of reaction mixtures were prepared by mixing $1 \mu \mathrm{g}(0,42 \mu \mathrm{M})$ of protein, $100 \mu \mathrm{M}$ $\mathrm{dCoA}$ and $100 \mu \mathrm{M}$ ATP in $25 \mathrm{mM} \mathrm{NH}_{4} \mathrm{HCO}_{3}(\mathrm{pH} 7.6$ ), $300 \mathrm{mM} \mathrm{NaCl}, 20 \mathrm{mM} \mathrm{KCl}$ and $10 \mathrm{mM}$ $\mathrm{MgCl}_{2}$. The reaction mixture was incubated at $37{ }^{\circ} \mathrm{C}$ for 1 hour, then, reaction was stopped by adding $100 \mu \mathrm{l}$ of acetonitrile (Sigma Aldrich, USA). Precipitated recombinant protein was separated by centrifugation at $20000 \mathrm{x} g$ at $4{ }^{\circ} \mathrm{C}$ for $20 \mathrm{~min}$.

The reaction samples were analyzed using the Dionex Ultimate 3000RS HPLC equipped with TSQ Quantiva MS detector (Thermo Fisher Scientific, USA). The ESI source was used for ionization in a positive mode. The HPLC solvent system consisted of $10 \mathrm{mM}\left(\mathrm{NH}_{4}\right)_{2} \mathrm{CO}_{3}(\mathrm{pH} 9.3)$ (A) and 97\% acetonitrile (B). $1 \mu \mathrm{l}$ of sample was injected in $50 \% \mathrm{~B}$ and the analysis was performed using the gradient of $15 \% \mathrm{~A}$ and $85 \% \mathrm{~B}$ for $3.5 \mathrm{~min}$ followed by an increase to $75 \%$ $\mathrm{A}$ and $25 \% \mathrm{~B}$ over $11.5 \mathrm{~min}$ and its continuation for $10 \mathrm{~min}$ with the SeQuant ${ }^{\circledR}$ ZIC $\AA-p H I L I C$ column $(5 \mu \mathrm{m}, 150 \mathrm{~mm} \times 2.1 \mathrm{~mm}$, Merck, USA), at a flow rate of $0.13 \mathrm{ml} / \mathrm{min}$.

\section{Circular dichroism spectroscopy}

ECD spectra were collected using a Jasco 1500 spectrometer (JASCO, Japan) in the 195 $-280 \mathrm{~nm}$ spectral range using a $0.01 \mathrm{~cm}$ cylindrical quartz cell. The experimental setup was as 
follows: $0.05 \mathrm{~nm}$ step resolution, $5 \mathrm{~nm} / \mathrm{min}$ scanning speed, $16 \mathrm{~s}$ response time, $1 \mathrm{~nm}$ spectral band width and 2 accumulations. After baseline correction, the spectra were expressed as molar ellipticity per residue $\theta\left(\mathrm{deg} \cdot \mathrm{cm}^{2} \cdot \mathrm{dmol}^{-1}\right)$. The protein samples were diluted in PBS buffer $(11.8$ $\mathrm{mM}$ phosphate ( $\mathrm{pH} 7.6), 137 \mathrm{mM} \mathrm{NaCl}, 5 \mathrm{mM} \mathrm{MgCl}_{2}, 2.7 \mathrm{mM} \mathrm{KCl}$ and $0.5 \mathrm{mM}$ DTT) with addition of $0-10 \mathrm{mM}$ urea. The blank spectrum of an aqueous buffer (with or without urea in a corresponding concentration) was used to correct the observed spectrum of the sample.

\section{Limited proteolysis}

Kinetic studies on specific proteolytic cleavage by Lys-C endoproteinase were performed as follows. First, recombinant proteins were diluted in Lys-C cleavage buffer $(25 \mathrm{mM}$ Tris $(\mathrm{pH}$ 8.0), $300 \mathrm{mM} \mathrm{NaCl}, 1 \mathrm{mM}$ EDTA, and $0.5 \mathrm{mM}$ TCEP) to the final concentration of $1 \mathrm{mg} / \mathrm{ml}$, and then reaction mixtures for proteolytic digestion were prepared by mixing $7 \mu \mathrm{lof} 1 \mathrm{mg} / \mathrm{ml}$ recombinant protein and $56 \mu \mathrm{l}$ of Lys-C cleavage buffer. After incubation at $37{ }^{\circ} \mathrm{C}$ for $10 \mathrm{~min}$ proteolytic cleavage was initiated by adding $7 \mu \mathrm{l}$ of $5 \mathrm{ng} / \mu \mathrm{l}$ Lys-C endoproteinase. After $0,2,5$, 10,20 and $40 \mathrm{~min}$ of incubation at $37^{\circ} \mathrm{C} 10 \mu \mathrm{l}$ of the reaction mixture was taken out, and Lys-C was inactivated by adding $2 \mu$ of $6 x$ SDS-PAGE sample buffer (375 mM Tris-HCl (pH 6.8), $9 \%$ SDS, $50 \%$ glycerol, $9 \%$ beta-mercaptoethanol and $0.03 \%$ bromophenol blue) followed by heating at $95{ }^{\circ} \mathrm{C}$ for $10 \mathrm{~min}$. All samples then were subjected to SDS-PAGE.

For quantitative evaluation of limited proteolysis the rate constants of proteolysis were determined by monitoring the disappearance of an intact protein in a proteolysis reaction by SDSPAGE. The areas of the bands corresponding to the intact proteins were estimated from the gels using the Image J program and then expressed as the amount of protein remaining after each time point. Assuming the pseudo-first order kinetics, the natural logarithms of the intact protein amounts were plotted against the time, and the plots were fitted with a first-order rate equation.

\section{Steady-state ANS fluorescence}

Steady-state fluorescence measurements were performed using CLARIO star microplate reader (BMG LABTECH, Germany). Protein samples were diluted to $2 \mu \mathrm{M}$ with ANS buffer (100 mM Tris, $300 \mathrm{mM} \mathrm{NaCl}, 20 \mathrm{mM} \mathrm{KCl}, 10 \mathrm{mM} \mathrm{MgCl}_{2}$ and $0.5 \mathrm{mM}$ DTT) and incubated with $0 ; 1 ; 10 ; 100$ and $1000 \mu \mathrm{M}$ of adenosine $5^{\prime}$-[ $\gamma$-thio]triphosphate tetralithium salt (ATP- $\gamma$-S, Sigma Aldrich, USA) at $20{ }^{\circ} \mathrm{C}$ for $30 \mathrm{~min}$. After incubation, 8-anilino-1-naphthalenesulfonic acid ammonium salt (ANS, Sigma Aldrich, USA) was added to the reaction mixtures to the final concentration of $400 \mu \mathrm{M}$, and the reaction mixtures were incubated for additional $5 \mathrm{~min}$. The final volume of each reaction mixture was $50 \mu \mathrm{l}$. The ANS fluorescence was excited at $380 \mathrm{~nm}$, and emission spectra were recorded between 410 and $650 \mathrm{~nm}$. To estimate the conformational changes induced upon $\mathrm{dCoA}$ binding the fluorescence intensity measurements were performed for protein samples in the presence of $200 \mu \mathrm{M}$ dCoA. All measurements were performed in triplicates and then averaged to yield steady-state fluorescence spectra of ANS binding.

\section{NMR spectroscopy}

NMR spectra were obtained using the Bruker@ Avance HD III $850 \mathrm{MHz}$ instrument, equipped with triple-resonance cryo-probe. Sample volume was $0.16 \mathrm{ml}$ in $3 \mathrm{~mm}$ NMR tubes, in 
a $50 \mathrm{mM}$ phosphate ( $\mathrm{pH} 7.6$ ) buffer, $280 \mathrm{mM} \mathrm{NaCl}, 10 \mathrm{mM} \mathrm{MgCl}_{2}, 20 \mathrm{mM} \mathrm{KCl}$ and $0.5 \mathrm{mM}$ TCEP. Protein concentration was $150 \mu \mathrm{M}$ for $3 \mathrm{D}{ }^{15} \mathrm{~N} /{ }^{1} \mathrm{H}$ NOESY-HSQC spectra, $30 \mu \mathrm{M}$ for DPCK-WT ATP titration, and $100 \mu \mathrm{M}$ for both aromatic amino acid-lacking mutants ATP titration. All proteins used in the study were ${ }^{15} \mathrm{~N}$ labeled. ATP titrations were followed using a series of standard 1D and 2D HN correlation spectra.

\section{Author Contributions}

MM and JM planned and performed the experiment and took part in writing the paper; VGG, VT and JV contributed significantly to the conception of the project, planned the experiments and helped with data analyses. AB, PS and LB performed the HPLC-MS, NMR and CD experiments respectively and helped with their analyses. AKD and $\mathrm{KH}$ planned the experiments, analyzed the data and wrote the paper.

\section{Acknowledgement}

We would like to thank Dr. Radko Souček for help with the amino acid analysis and Dr. Tereza Ormsby, Dr. Rozálie Hexnerová and Dr. Václav Veverka for helpful suggestions. This work was supported by the Czech Science Foundation (GAČR) grant number 17-10438Y, project SVV260572/2020 (VT and MM) and by the project BIOCEV (CZ.1.05/1.1.00/02.0109), from the European Regional Development Fund. We would also like to acknowledge the facility and support of the CMS-Biocev ("Biophysical techniques") supported by MEYS ČR (LM2018127).

\section{References}

1. H. J. Cleaves II, The origin of the biologically coded amino acids. J. Teor. Biol. 263:4, 490-498 (2010).

2. G. K. Philip, S. J. Freeland, Did evolution select a nonrandom "alphabet" of amino acids? Astrobiology. 11:3, 235-240 (2011).

3. M. Ilardo, M. Meringer, S. Freeland, B. Rasulev, H. J. Cleaves II, Extraordinarily Adaptive Properties of the Genetically Encoded Amino Acids. Sci. Rep. 5, 9414 (2015).

4. M. Ilardo et al., Adaptive Properties of the Genetically Encoded Amino Acid Alphabet Are Inherited from Its Subsets. Sci. Rep. 9, 12468 (2019).

5. V. Tretyachenko et al., Random protein sequences can form defined secondary structures and are welltolerated in vivo. Sci. Rep. 7, 15449 (2017).

6. J. Tanaka, N. Doi, H. Takashima, H. Yanagawa, Comparative characterization of random-sequence proteins consisting of 5, 12, and 20 kinds of amino acids. Protein Sci. 19:4, 786-795 (2010). 
7. M. S. Newton, D. J. Morrone, K. H. Lee, B. Seelig, Genetic Code Evolution Investigated through the Synthesis and Characterisation of Proteins from Reduced-Alphabet Libraries. ChemBioChem. 20:6, 846-856 (2019).

8. P. G. Higgs, R. E. Pudritz, A Thermodynamic Basis for Prebiotic Amino Acid Synthesis and the Nature of the First Genetic Code. Astrobiology. 9:5, 483-490 (2009).

9. E. N. Trifonov, Consensus temporal order of amino acids and evolution of the triplet code. Gene. 261:1, 139-151 (2000).

10. M. Granold, P. Hajieva, M. I. Toşa, F. D. Irimie, B. Moosmann, Modern diversification of the amino acid repertoire driven by oxygen. Proc. Natl. Acad. Sci. U.S.A. 115:1, 41-46 (2018).

11. G. P. Fournier, E. J. Alm, Ancestral Reconstruction of a Pre-LUCA Aminoacyl-tRNA Synthetase Ancestor Supports the Late Addition of Trp to the Genetic Code. J. Mol. Evol. 80:3-4, 171-185 (2015).

12. X.L. Yang, F.J. Otero, R.J. Skene, D.E. McRee, P. Schimmel, L.R. de Pouplana. Crystal structures that suggest late development of genetic code components for differentiating aromatic side chains. Proceedings of the National Academy of Sciences. 100(26):15376-80 (2003).

13. D. S. Riddle et al., Functional rapidly folding proteins from simplified amino acid sequences. Nat. Struct. Biol. 4:10, 805-809 (1997).

14. S. Akanuma, T. Kigawa, S. Yokoyama, Combinatorial mutagenesis to restrict amino acid usage in an enzyme to a reduced set. Proc. Natl. Acad. Sci. U. S. A. 99:21, 13549-13553 (2002).

15. L. M. Longo, J. Lee, M. Blaber, Simplified protein design biased for prebiotic amino acids yields a foldable, halophilic protein. Proc. Natl. Acad. Sci. U. S. A. 110:6, 2135-2139 (2013).

16. R. Shibue et al., Comprehensive reduction of amino acid set in a protein suggests the importance of prebiotic amino acids for stable proteins. Sci. Rep. 8, 1227 (2018).

17. A. D. Solis, Reduced alphabet of prebiotic amino acids optimally encodes the conformational space of diverse extant protein folds. BMC Evol. Biol. 19:1, 158 (2019).

18. M. Kimura, S. Akanuma, Reconstruction and Characterization of Thermally Stable and Catalytically Active Proteins Comprising an Alphabet of $\sim 13$ Amino Acids. J. Mol. Evol. 88:4, 372-381 (2020).

19. A. Campen, R.M. Williams, C.J. Brown, J. Meng, V.N. Uversky, A.K. Dunker, TOP-IDP-scale: a new amino acid scale measuring propensity for intrinsic disorder. Protein Pept Lett. 15:956-963 (2008).

20. S.K. Burley, G.A. Petsko, Aromatic-aromatic interaction: a mechanism of protein structure stabilization. Science. 229:23-28 (1985).

21. E. Di Mauro, A. K. Dunker, E. N. Trifonov, "Disorder to Order, Nonlife to Life: In the Beginning There Was a Mistake" in Genesis - In The Beginning. Cellular Origin, Life in Extreme Habitats and Astrobiology vol. 22, J. Seckbach, Eds. (Springer, 2012), pp. 415-435.

22. P. Romero, Z. Obradovic, X. Li, E. C. Garner, C. J. Brown, A. K. Dunker. Sequence complexity of disordered protein. Proteins. 42:1, 38-48 (2001). 
23. C.J. Oldfield, A.K. Dunker, Intrinsically disordered proteins and intrinsically disordered protein regions. Annu Rev Biochem. 83:553-584 (2014).

24. K. Peng, P. Radivojac, S. Vucetic, A.K. Dunker, Z. Obradovic, Length-dependent prediction of protein intrinsic disorder. BMC Bioinformatics. 7:208 (2006).

25. Brooks DJ, Fresco JR. Increased frequency of cysteine, tyrosine, and phenylalanine residues since the last universal ancestor. Mol Cell Proteomics. 1:125-131 (2002).

26. L. Sumbalova, J. Stourac, T. Martinek, D. Bednar, J. Damborsky, HotSpot Wizard 3.0: web server for automated design of mutations and smart libraries based on sequence input information. Nucleic Acids Res. 46:W1, W356-W362 (2018).

27. A. Nurkanto et al., Biochemical, Metabolomic, and Genetic Analyses of Dephospho Coenzyme A Kinase Involved in Coenzyme A Biosynthesis in the Human Enteric Parasite Entamoeba histolytica. Front Microbiol. 9, 2902 (2018).

28. A. Seto et al. ATP-induced structural change of dephosphocoenzyme A kinase from Thermus thermophilus HB8. Proteins. 58:1, 235-242 (2005).

29. G. V. Semisotnov et al., Sequential mechanism of refolding of carbonic anhydrase B. FEBS Lett. 224:1, 9-13 (1987).

30. G. Walia, A. Surolia, Insights into the regulatory characteristics of the mycobacterial dephosphocoenzyme A kinase: implications for the universal CoA biosynthesis pathway. PLoS One. 6:6, e21390 (2011).

31. K. Vamvaca, B. Vögeli, P. Kast, K. Pervushin, D. Hilvert, An enzymatic molten globule: efficient coupling of folding and catalysis. Proc. Natl. Acad. Sci. U. S. A. 101:35, 12860-12864 (2004).

32. K. Pervushin, K. Vamvaca, B. Vögeli, D. Hilvert, Structure and dynamics of a molten globular enzyme. Nat. Struct. Mol. Biol. 14:12, 1202-1206 (2007).

33. P.J. Sapienza, L. Li, T. Williams, A.L. Lee, C.W. Carter Jr. An ancestral tryptophanyl-tRNA synthetase precursor achieves high catalytic rate enhancement without ordered ground-state tertiary structures. ACS chemical biology. 11(6):1661-8 (2016).

34. F. Huang, C. Oldfield, J. Meng, W.L. Hsu, B. Xue, V.N. Uversky, P. Romero, A.K. Dunker, Subclassifying disordered proteins by the CH-CDF plot method. Pac Symp Biocomput. 128-39 (2012). 


\section{Figures}

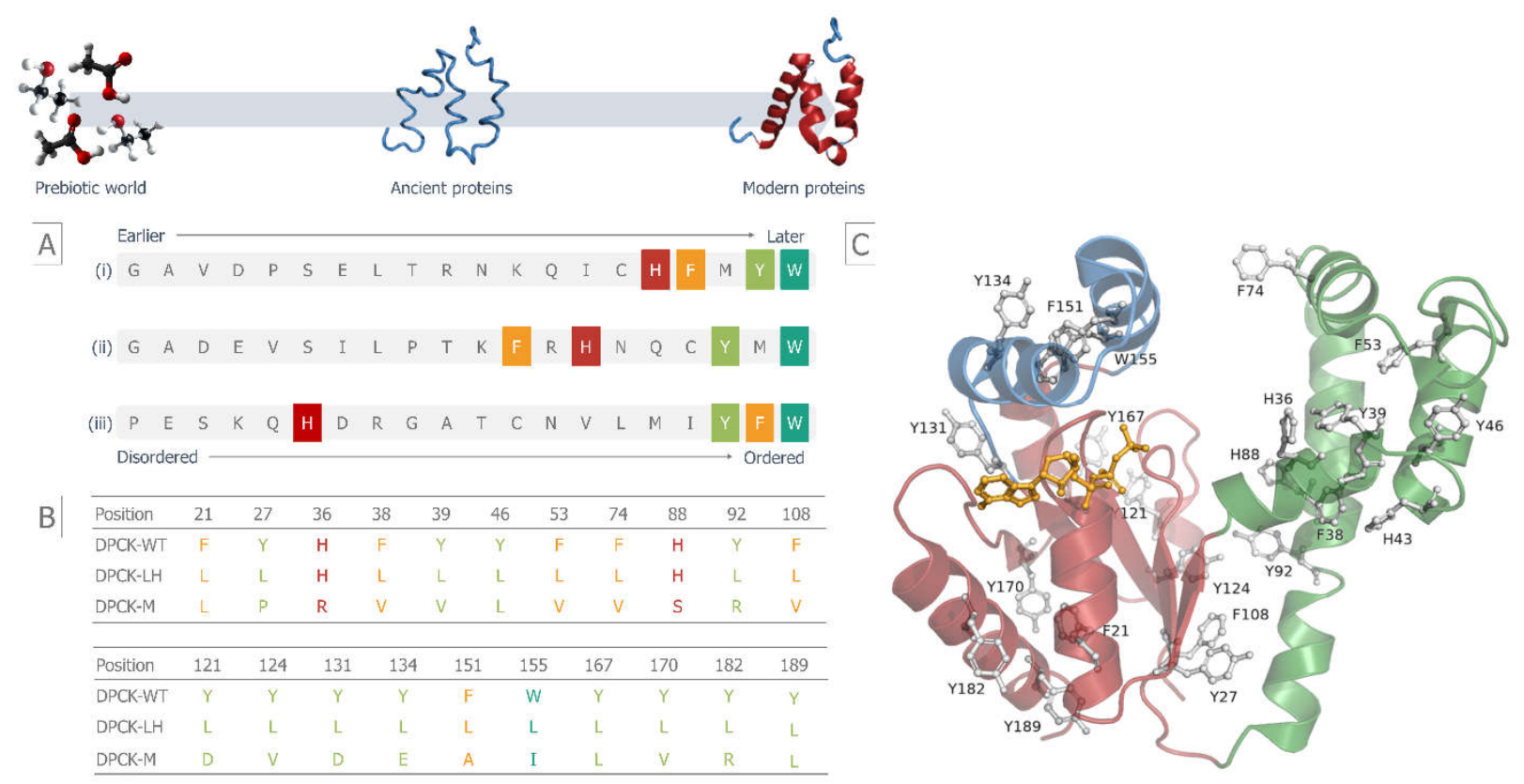

Fig. 1. Sequence design of DPCK variants lacking aromatic amino acids.

(A) The chronological order and ranking of 20 amino acids: (i) order of appearance in the genetic code derived by meta-analyses by Trifonov (9); (ii) order of appearance based on the prebiotic availability and thermodynamic stability by Higgs and Pudritz (8); (iii) ranking based on their increasing propensity to promote structure (18)

(B) Aromatic amino acid content of DPCK-WT, $-L H$ and $-M$ variants

(C) Aromatic residues highlighted in the structure of DPCK from Aquifex aeolicus (PDB ID 2IF2), with ATP molecule positioned based on structural alignment with the H. influenzae DPCK complex with ATP (PDB ID IJJV) 
(A)

\begin{tabular}{|c|c|c|c|c|c|}
\hline Enzyme & Substrate & $\mathbf{K}_{\mathbf{m}}(\boldsymbol{\mu} \mathbf{M})$ & $V_{\max }(\mu M / \min )$ & $k_{\text {cat }}(1 / \mathrm{min})$ & $K_{\text {cat }} / K_{m}\left(1 /\left(\mu M^{*} \min \right)\right)$ \\
\hline \multirow[t]{3}{*}{ DPCK-WT } & dCoA (with $200 \mu \mathrm{M} \mathrm{ATP)}$ & $24.3 \pm 1.7$ & $1.57 \pm 0.17$ & $49.0 \pm 5.2$ & 2.02 \\
\hline & ATP (with $200 \mu \mathrm{M}$ dCoA) & $12.7 \pm 0.3$ & $1.41 \pm 0.05$ & $43.8 \pm 1.5$ & 3.45 \\
\hline & ATP (without dCoA) & n.d. & n.d. & n.d. & n.d. \\
\hline \multirow[t]{3}{*}{ DPCK-LH } & dCoA (with $200 \mu \mathrm{M} \mathrm{ATP})$ & $>200$ & n.d. & n.d. & n.d. \\
\hline & ATP (with $200 \mu \mathrm{M} \mathrm{dCoA}$ ) & $65.9 \pm 4.5$ & $0.30 \pm 0.01$ & $1.42 \pm 0.03$ & 0.0215 \\
\hline & ATP (without dCoA) & $40.2 \pm 3.8$ & $0.11 \pm 0.013$ & $0.52 \pm 0.03$ & 0.0130 \\
\hline \multirow[t]{3}{*}{ DPCK-M } & dCoA (with $200 \mu \mathrm{M} \mathrm{ATP)}$ & n.d. & n.d. & n.d. & n.d. \\
\hline & ATP (with $200 \mu \mathrm{M}$ dCoA) & $32.3 \pm 3.4$ & $0.088 \pm 0.003$ & $0.23 \pm 0.01$ & 0.0071 \\
\hline & ATP (without dCoA) & $29.2 \pm 2.5$ & $0.085 \pm 0.002$ & $0.22 \pm 0.01$ & 0.0075 \\
\hline
\end{tabular}

n.d. - not detectable

(B)

\section{DPCK-WT}
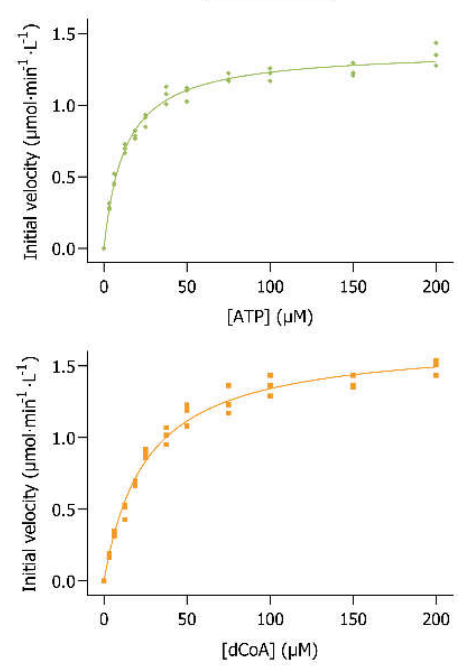
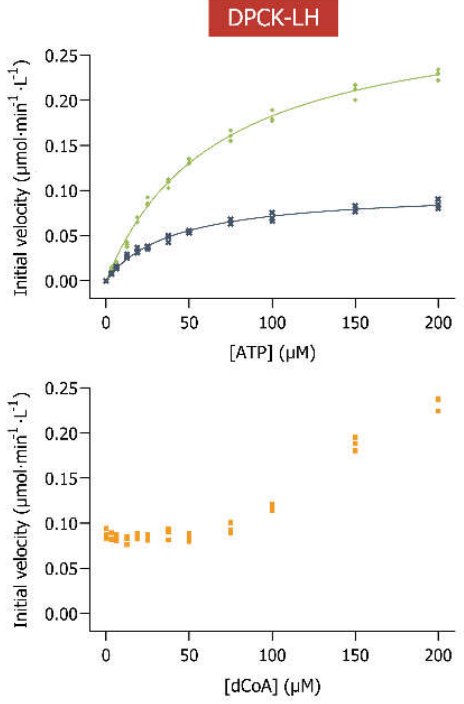
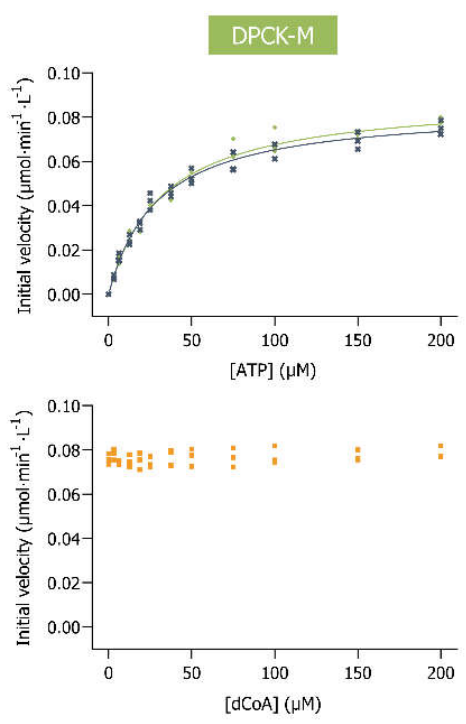

$\multimap$ with $0-200 \mu \mathrm{M}$ ATP and $200 \mu \mathrm{M} \mathrm{dCOA} \rightarrow$ with $0-200 \mu \mathrm{M}$ ATP and without dCOA — with 0-200 $\mu \mathrm{M}$ dCoA and $200 \mu \mathrm{M}$ ATP

Fig. 2. Kinetic characterization of DPCK variants.

(A) Summary of catalytic efficiencies

(B) Michaelis-Menten plots of DPCK proteins for initial velocity versus (TOP) ATP concentration, monitoring production of ADP; reactions were performed without and with $200 \mu \mathrm{M} d C o A$ to estimate ATPase and phosphotransferase activities of enzymes. (BOTTOM) dCoA concentration, monitoring production of ADP. Reactions were performed in $15 \mathrm{mM}$ Hepes (pH 7.4), $20 \mathrm{mM} \mathrm{NaCl}, 1 \mathrm{mM} \mathrm{EGTA}, 0.02 \%$ Tween-20, $10 \mathrm{mM}$ $\mathrm{MgCl}_{2}$, and $0.1 \%$ bovine gamma globulin, and was initiated with ATP. The lines represent nonlinear least squares fits. 
bioRxiv preprint doi: https://doi.org/10.1101/2020.11.11.377994; this version posted November 11,2020 . The copyright holder for this preprint (which was not certified by peer review) is the author/funder, who has granted bioRxiv a license to display the preprint in perpetuity. It is made available under aCC-BY-NC-ND 4.0 International license.

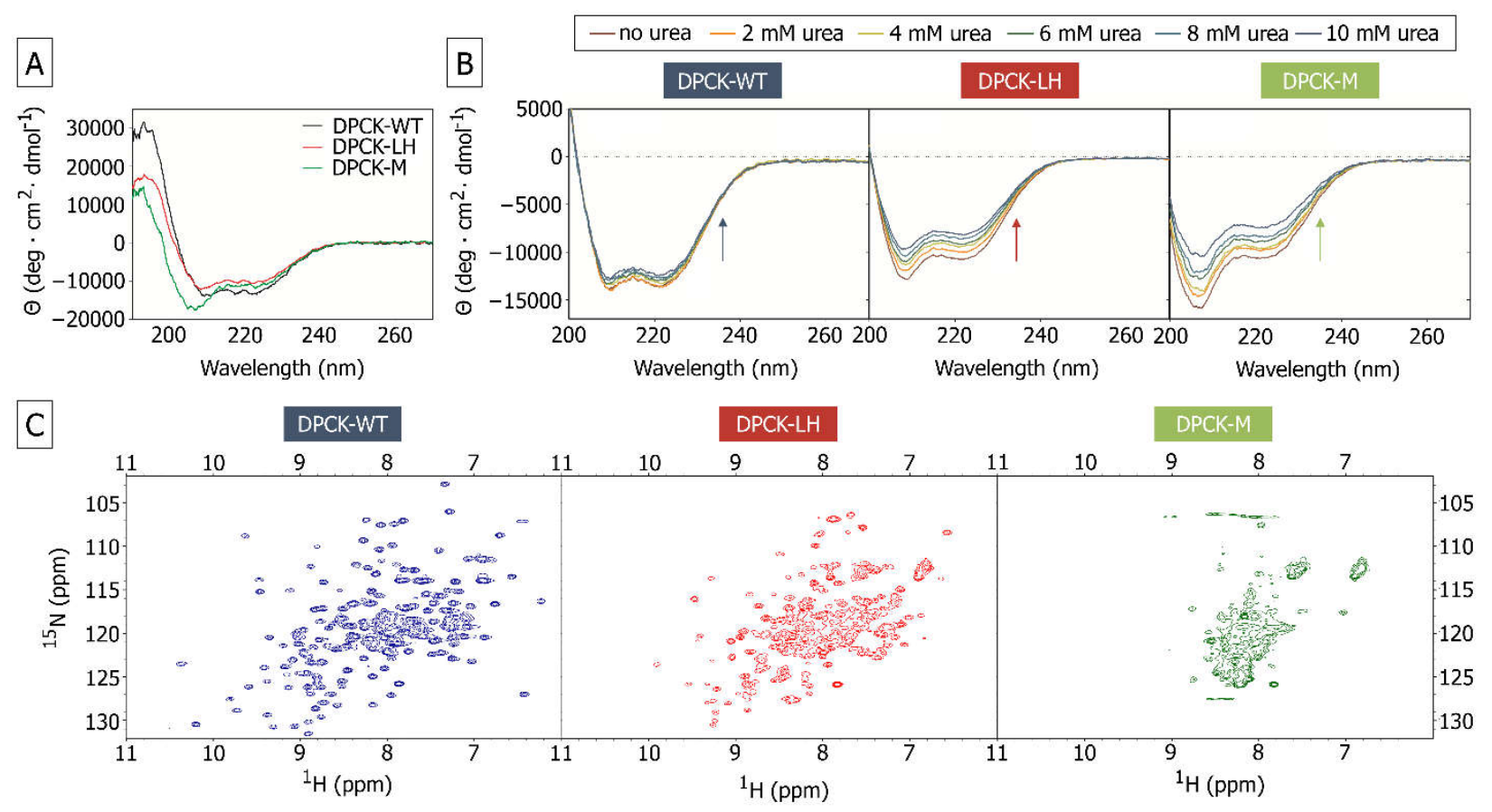

Fig. 3. Secondary and tertiary structure characterization of DPCK variants.

(A) Far-UV CD spectra of DPCK proteins. The spectra were collected in PBS buffer (11.8 mM phosphate (pH 7.6), $137 \mathrm{mM} \mathrm{NaCl}, 5 \mathrm{mM} \mathrm{MgCl}$, $2.7 \mathrm{mM} \mathrm{KCl}$ and $0.5 \mathrm{mM} \mathrm{DTT}$ )

(B) Far-UV CD spectra of DPCK proteins measured at 0-10 $\mathrm{mM}$ urea. The spectra were collected in PBS buffer (11.8 mM phosphate (pH 7.6), $137 \mathrm{mM} \mathrm{NaCl,5} \mathrm{mM} \mathrm{MgCl}, 2.7 \mathrm{mM} \mathrm{KCl}$ and $0.5 \mathrm{mM} \mathrm{DTT}$ ) with addition of $0-10$ mM urea

(C) $2 D$ NMR of DPCK proteins. The spectra were collected in $50 \mathrm{mM}$ phosphate (pH 7.6), $280 \mathrm{mM} \mathrm{NaCl,} 20 \mathrm{mM}$ $\mathrm{KCl}, 10 \mathrm{mM} \mathrm{MgCl}$, and $0.5 \mathrm{mM} \mathrm{TCEP}$. 
bioRxiv preprint doi: https://doi.org/10.1101/2020.11.11.377994; this version posted November 11,2020 . The copyright holder for this preprint (which was not certified by peer review) is the author/funder, who has granted bioRxiv a license to display the preprint in perpetuity. It is made available under aCC-BY-NC-ND 4.0 International license.

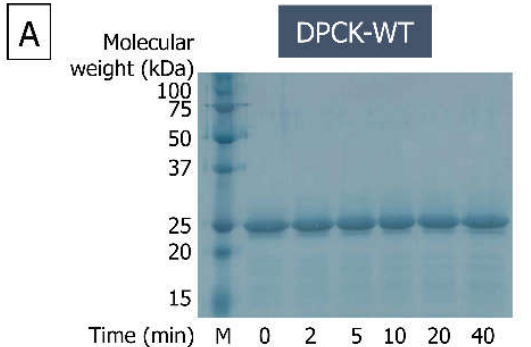

B

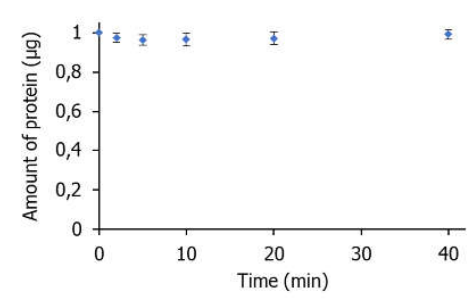

C
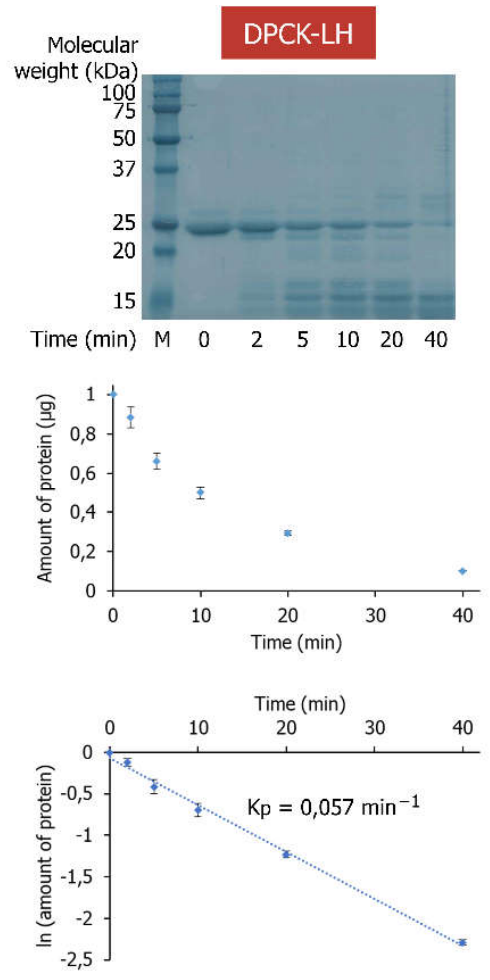
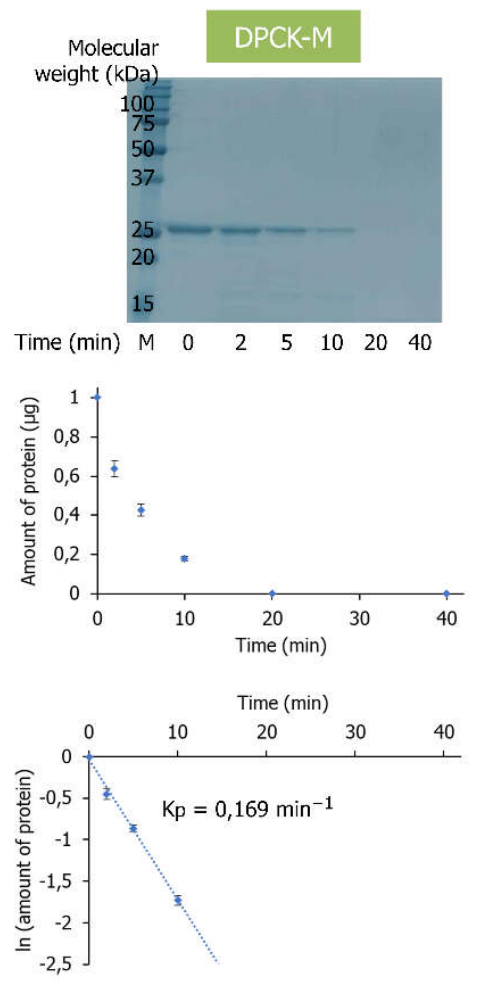

Fig. 4. Limited proteolysis of DPCK proteins.

(A) 14\% SDS-polyacrylamide gels visualized by imidazole-zinc staining after SDS-PAGE with the protein samples exposed to Lys-C endoproteinase for different times.

(B) Graphs representing the amount of the proteins remaining at each time point.

(C) Determination of proteolysis rate constants $(K p)$ assuming pseudo-first order of proteolytic reactions. 

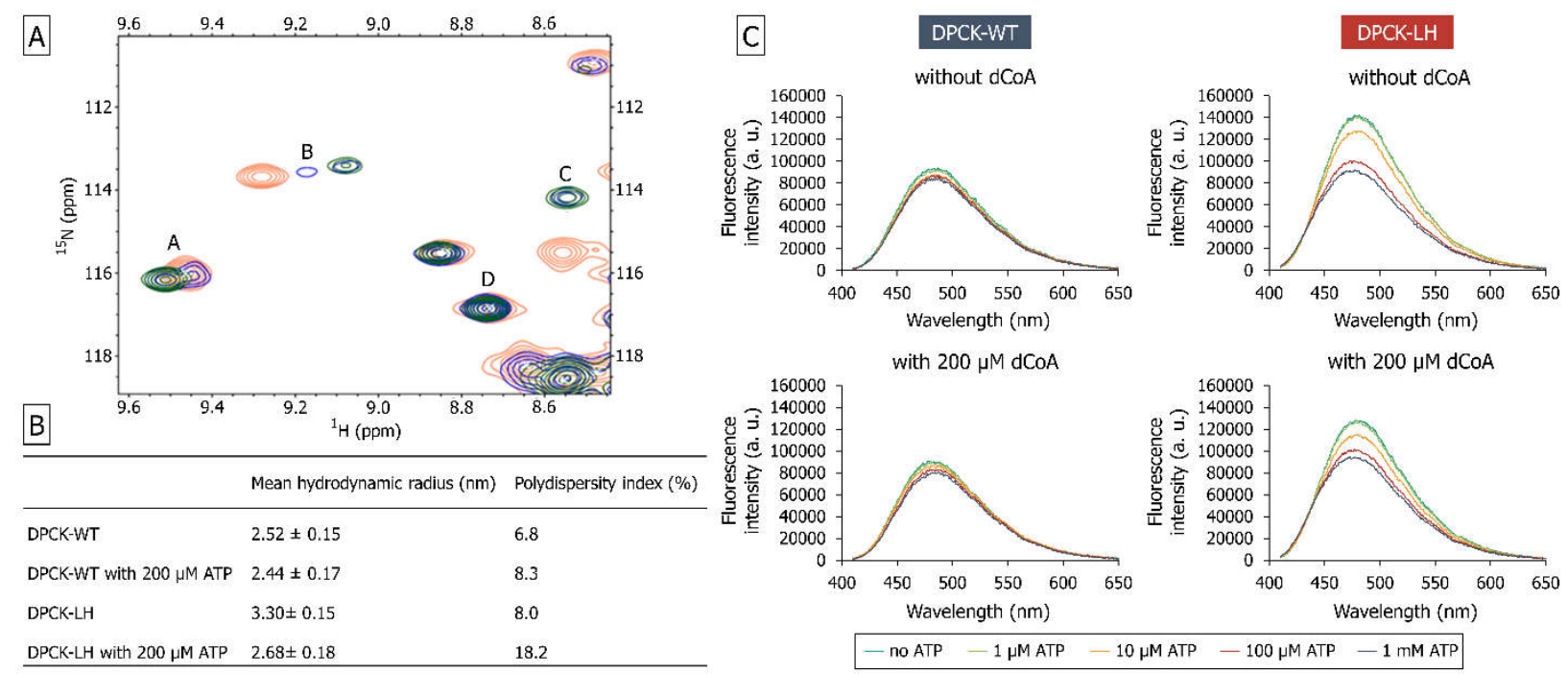

Fig. 5. Structural Characterization of DPCK-WT and -LH upon substrate binding (A) An exemplary close-up of DPCK-LH 2D NH NMR spectra induced by ATP binding (red - free protein (100 $\mu M)$, blue - $300 \mu M$ ATP, green - $1000 \mu M$ ATP).

(B) Mean hydrodynamic radius of DPCK-WT and -LH variants with and without $200 \mu M$ ATP measured by dynamic light scattering.

(C) The steady-state fluorescence spectra of ANS binding at excitation wavelength $380 \mathrm{~nm}$. The spectra were measured at different concentrations of ATP (with and without $200 \mu \mathrm{MdCoA}$ ), and each spectrum is the average of three individual scans. The fluorescence was recorded between $410-650 \mathrm{~nm}$ after exciting the protein solution at $380 \mathrm{~nm}$. 